\title{
ESTUDO DE EVENTOS CO-SISMOGÊNICOS BRASILEIROS
}

\author{
Thiago de Almeida Santos ${ }^{1}$ \\ Virgínia Klausner ${ }^{2}$ \\ Márcio T. A. H. Muella ${ }^{3}$ \\ Valdir Gil Pillat ${ }^{4}$
}

Resumo: Este trabalho, relacionado com o evento sísmico de 16 de Setembro de 2015, em Illapel, Chile, foca na análise de variações geomagnéticas, principalmente na caracterização e situação em que se dão, a fim de contribuir para uma melhor compreensão dos processos físicos envolvidos no acoplamento Litosfera-Atmosfera-lonosfera (LAI). Para isto, foram utilizados registros de magnetômetros fluxgate medidos em superfície fornecido pela rede EMBRACE. A metodologia de análise consiste na decomposição do sinal por bandas de frequência, isto é, Decomposição de Modo Empírico (EMD). O resultado alcançado no momento é a caracterização de efeitos magnéticos co-sismogênicos em território brasileiro causados pelo evento sísmico citado. Portanto, estudos como este se mostram indispensáveis e importantes não apenas no ponto de vista científico, mas também pela possibilidade de contribuição para uma futura condição de previsão e de potencial de alerta de catástrofes.

Palavras-chave: Terremoto; Propagação de ondas; Magnetogramas.

\footnotetext{
${ }^{1}$ Engenharia Elétrica/UNIVAP, Brasil. E-mail: thiagoalmeidamusico@hotmail.com.

2 IP\&D/UNIVAP, Brasil. E-mail: virginia@univap.br.

3 IP\&D/UNIVAP, Brasil. E-mail: mmuella@univap.br.

4 IP\&D/UNIVAP, Brasil. E-mail: valdirgp@univap.br.
} 